\title{
Implementation of E-health Record Systems in Australia
}

\author{
Jun Xu, Xiangzhu Gao, Golam Sorwar \& Peter Croll \\ Southern Cross Business School, Southern Cross University \\ Lismore, NSW 2480, Australia \\ E-mail: jun.xu@scu.edu.au
}

\begin{abstract}
Consideration of e-health record systems in Australia started in 2000. Based on the effort to develop stand-alone and state-wide systems, the national Personally Controlled Electronic Health Record system was released on July 1, 2012. However this system has been widely criticised, although stakeholders are in favour of a national system. To overcome the challenges to the system and achieve its benefits, recommendations are provided for improving system effectiveness and usability, and adopting applicable government policies.
\end{abstract}

Keywords: E-health, E-health Record Systems, PCEHR System, Australia

\section{Introduction}

With the exponential growth of Internet penetration coupled with advances in networking and information communication technologies, the e-health movement has been introduced and accepted as an essential and important element in healthcare systems. The adoption of e-health initiatives are expected to bring a paradigm shift in traditional healthcare system by reducing medical errors, enhancing healthcare quality, minimising healthcare costs, and empowering consumers to understand their healthcare needs and make informed decisions on their healthcare. Among these initiatives are practice management (e.g. practice scheduling, prescribing and billing), information sourcing and sharing, service delivery (e.g. chronic disease support and tele-health), remote care management and wellness, clinical decision support (e.g. aid in collaborative diagnosis, treatment and care processes), e-health record (EHR) and public health intelligence ${ }^{1}$. As a health information source, the EHRs underpin all the others. Since 2000, an enormous effort has been made in Australia to develop EHR systems. On July 1st, 2012, the Australian government released the first version of the Personally Controlled Electronic Health Record (PCEHR) system.

The International Organization for Standardization (ISO) defines EHRs as repositories of information regarding the health status of a subject of care in computer processable form ${ }^{2}$. It is widely believed in Australia that systematic EHRs provide great opportunities to improve the quality and safety of healthcare; reduce costs; improve continuity and health outcomes for patients; save lives, time, and money; make Australian health system more efficient; and provide every Australian with equitable access to healthcare $^{3,4}$. Technologically, Australia possesses the necessary foundation for implementing a national EHR system. On the one hand, almost all general practitioners (GPs) and pharmacies are computerassisted. Most public hospitals are in various stages of computerisation/digitisation ${ }^{5}$. The majority of allied health professionals and medical specialists have regularly used computers for accessing online clinical reference tools, online training and education, billing and patient rebates, patient booking and scheduling as well as viewing diagnostic imaging results ${ }^{1}$. More than $96 \%$ of GPs have access to the Internet in offices, and $95 \%$ of GPs use electronic patient medical records ${ }^{4}$. On the other hand, more than $85 \%$ of Australians have access to the Internet ${ }^{7}$. The wide use of the Internet in Australian public contributes to the good foundation for EHR systems in Australia.

Consideration of EHR systems in Australia started in $2000^{8}$. MediConnect, which electronically collected and 
stored information about medicines and exchanged such information among doctors, pharmacists and individuals, is the first system of this kind. In 2004, MediConnect completed its field test in Launceston and Ballarat and ceased as a stand-alone system on December 31, 2004. As the largest e-health trials in Australia by then, the completed field test of MediConnect provided vital experience in implementing an EHR system, and the key components of MediConnect and lessons learned from deploying the system was used to assist in the subsequent state-wide implementation of HealthConnect, which is a network of EHRs and involves electronically collecting, storing and exchanging individuals' health information on the network ${ }^{9}$. The HealthConnect program, which started in 2005 and completed in 2009, eventually consisted of a set of different projects undertaken individually by all the states/territories except Queensland. The program provided significant gains in the establishment of ehealth infrastructure across Australia ${ }^{10}$. In the period of 2010 to 2012, the Australian government invested \$467 million in the first release of the national PCEHR system, which delivers core functionality of the eventual system $^{8}$. More functions, elements and links will be developed and made available gradually. Currently, many medical practices are updating or waiting for updated IT infrastructure for the system. In 2012, the Australian government committed further investment for refining and deploying the PCEHR system.

According to an estimate based on the economic modelling undertaken by Deloitte Consulting in 20102011, the PCEHR system could generate approximately $\$ 11.5$ billion in net direct benefits over the period of 2010 to 2025, \$9.5 billion to Australian governments and \$2 billion to the private sector including households, GPs, specialists, allied health clinics, private hospitals and private health insurance providers $^{11}$. Through innovative e-health initiatives like the PCEHR system, Australia has developed legislations and infrastructure that will benefit future e-health projects $^{12}$. According to Peter Fleming, CEO of the National E-health Transition Authority (NEHTA), Australia is expected to spend $20 \%$ of its gross domestic product on healthcare by 2020, and the estimated savings arising from e-health initiatives are $\$ 7$ billion.

However, there is very thin evidence for that the ehealth implementations have improved healthcare in Australian context ${ }^{13}$, and there is a long way to go in order to realise the benefits. The current release of the PCEHR system is far from mature and suffers criticisms from major stakeholders. The system is facing various challenges, and users, both individuals and healthcare providers, are not enthusiastic in registering with the system and using the system.

\section{Current Status}

\subsection{Adoption of EHR}

On average, every year an Australian has 22 interactions with healthcare providers, including 4 visits to GPs, 12 prescriptions, 3 visits to specialists ${ }^{11}$, and most of the information of these interactions has been held in paperbased files or non-shared databases. The medical information may be inconsistent between files, inaccurate because of lack of standards, incorrect because of manual operation, and is not available in emergency situations. It is estimated that 5,000 Australians die each year due to adverse medical events; $18 \%$ of medical errors in Australia occur from inadequate information; nearly 30\% unplanned hospital admissions are associated with prescribing errors; and approximately $13 \%$ of healthcare provider consultation suffers missing information ${ }^{3,4,14}$. Patients may need to undergo the same tests with different healthcare providers. It is not unusual that same questions are asked every time when a patient deals with a different provider. A solution to these problems is EHRs, which can include such information as patients' prescribed medications, test results, care plans, immunisation records, health alerts, event summaries, discharge summaries, Medicare data, and personal data. Real-time and convenient access to such information will no doubt improve the quality of healthcare, especially in emergency situations and special conditions ${ }^{15}$.

Jha et al. ${ }^{16}$ studied the use of health information technology in seven countries including US, Canada, UK, Germany, Netherlands, Australia and New Zealand. According to their report, Australia, along with UK, Netherlands and New Zealand, has nearly universal use of EHRs among more than $90 \%$ of GPs, but the adoption rate of EHRs in hospitals is less than $10 \%$. Jha et al. ${ }^{16}$ argued that only those nationals willing to put in significant investments and take up the challenge of developing standards and interchanges will be able to succeed in their EHR systems, and be able to provide the benefits of EHRs to their people. Australia is one of 
such nationals and has invested significantly in e-health. Over \$2 billion was spent in e-health in 2010 alone $^{17}$. For the PCEHR system, on top of the $\$ 467$ million invested for the period of July 2010 to June 2012, Australian government has allocated further \$233.7 million for the period of July 2012 to June $2014^{18}$.

\subsection{National Approach}

EHR initiatives have been widely viewed as an opportunity to have fundamental improvement in the public health sector. Most industrial countries have adopted the approach of national EHR system ${ }^{19}$. Australia has also taken a national approach in implementing an EHR system for individuals. The Australian public has demonstrated strong support to the establishment of EHR system and the national approach. An NEHTA study ${ }^{20}$ showed that more than $80 \%$ of 2,700 nationwide participants strongly supported the idea of establishing an EHR system for individuals, and $90 \%$ believed that the federal government should manage the implementation and operation of the system. In the same study, major advantages and disadvantages of such a system are identified. The major advantages include: (1) immediate access to important medical information to save lives and improve health services; (2) ease for patients, especially chronic illness sufferers, to know that their records are updated, accurate and readily available; and (3) ubiquitous health records (health records can be accessed everywhere). The major disadvantages consist of: (1) security breach of personal health information by hackers, (2) inappropriate use of personal health information (e.g. by insurance firms or employers against their clients or employees), and (3) high costs of the system.

\subsection{Progress of PCEHR}

Main events leading to releasing the PCEHR system are as follows.

- In 2005, the NEHTA was established to coordinate the national EHR project.

- In 2008, the National E-health Strategy ${ }^{21}$ was developed to present a blueprint for the national EHR project.

- In 2010, development of the PCEHR system started based on the previous initiatives of MediConnect and HealthConnect.

- In 2010, the Healthcare Identifiers Act $2010^{22}$ was issued, which ensures that healthcare is matched to the health information. The correct match is achieved by assigning an identifier to each healthcare provider or healthcare recipient. The identifiers will be used in the PCEHR system.

- In 2010, pilot-testing of the PCEHR system was conducted in 12 nationally selected and funded sites. The participants are mothers and newborns, people with chronic disease and those in aged and palliative care settings ${ }^{3}$.

- In 2011, Privacy Impact Assessment Report ${ }^{23}$ regarding PCEHR was prepared for the Department of Health and Ageing. The report analyses possible impacts on the privacy of personal information in the PCEHR system, and recommends options for managing, minimising or eradicating negative impacts.

- In 2011, the Australian government released Concept of Operations: Relating to the Introduction of a Personally Controlled Electronic Health Record System ${ }^{24}$. This document provides an overview of the PCEHR system, identifies stakeholders and describes how the system would work. It will be periodically updated with the further development of the PCEHR system by addressing identified needs and concerns along the implementation process.

- In 2012, the Practice Incentives Program (PIP) eHealth Incentive was announced by the Department of Health and Ageing. General practices will be required to participate in the PCEHR program or become ineligible for the eHealth PIP $^{25}$.

- In 2012, the Personally Controlled Electronic Health Records Act 2012 was released to support the effective operation of the PCEHR system. The Act covers four main areas: (1) governance of the system; (2) registration of individuals, healthcare provider organisations, individual healthcare providers, and other actors in the system; (3) collection, use and disclosure of health information included in a registered individual's eHealth record; and (4) penalties and enforcement. It has first time required mandatory privacy breach reporting obligations in regulation in Australia ${ }^{26}$.

- $\quad$ On July 1st 1012, the PCEHR system was released. Australians can register with the system, create and manage their personal health record online.

- The government is working with healthcare providers and the ICT industry to build on the capabilities provided by the PCEHR system in order to incrementally expand the breadth and depth of adoption over time ${ }^{11}$. 


\section{Challenges and Issues}

\subsection{Impact of Policy and Economic Uncertainty}

Government policies affect the development of EHR systems. Although both the current government and the opposition support e-health, the opposition has been debating against the PCEHR system, which was implemented by the current government. The federal opposition spokesman told eHealthspace.org that if coalition had won government in 2007, it would have done things differently for an e-health system ${ }^{27}$. If the opposition wins the next election in 2013, Australia's EHR system may become obviously different from what it is today. The change in state/territory governments also impacts the delivery, management and success of the PCEHR system. In addition, the uncertainty of Australia's economy, especially the unstable commodity market, will affect governments' financial ability and determination to see the project through, which will be a very long, expensive and daunting journey. On the other hand, the full benefits of the PCEHR system will be realised by all the stakeholders over the next 10 years, according to NEHTA ${ }^{28}$.

\subsection{Issue of Unified Approach}

Australia's multi-tier government system and large private sector have made the design and implementation of e-health systems extremely complex. For example, the federal government provides funds to both individual (via Medicare) and hospital services, and state/territory governments provide more than 50\% funding to public hospitals. The NEHTA, which manages the PCEHR project, is jointly funded by federal government and state/territory governments. Federal government, state/territory governments and local governments can legislate or determine laws, regulations, and/or code of practices respectively. Differences exist in privacy policies, community services and other factors. There is widespread uncertainty surrounding the adoption of e-health in Australia from political, policy, administrative, clinical, and patient perspectives ${ }^{29}$.

A unified approach should be adopted to ensure the successful implementation of the national $\mathrm{PCEHR}^{30}$. According to European experience, centralised health systems can achieve a far higher adoption rate ${ }^{29}$.

While the PCEHR approach provides the required leadership and the focus on delivering an integrated system nationally, it could very likely ignore certain important local elements. According to Deutsch et al. ${ }^{19}$, a review report by Boston Consulting Group had revealed that inadequate stakeholder management and regional cooperation is a problem with the PCEHR project. In addition, there is a large private health sector in Australia. The concept of patient-controlled health information could be confronting to some health practitioners who view patient records as competitive information $^{31}$. They do not share the information with others, and do not encourage the registration with the system.

Looking after local and stakeholders' needs is very critical for the success of the national PCEHR system since state/territory governments are managers and operators of actual public health services and are regulating local health professionals. A good balance has to be achieved, and a good combined solution of localisation and centralisation should be adopted, but without losing the focus on integration, interoperability, shared learning, and aligned implementation efforts ${ }^{32}$.

\subsection{Issue of Transparent NEHTA Operation}

There is a long way to go for the PCEHR system to be in its full operation, and it remains unclear when the project will be completed ${ }^{33}$. In the remaining process the NEHTA should improve its operation. The PCEHR project has been blamed for lack of transparency. In the 2007 report by Boston Consulting Group, poor transparency and lack of communication regarding the operations of NEHTA were cited as two major problems $^{19}$. During the past five years, NEHTA has acted on this issue, however it can be argued that there is still a lot of room for NEHTA to improve. For example, the federal government recently terminated its contract with IBM, which was contracted for building an essential element of the PCEHR system, but so far no clear clarification has been given for such a dramatic action $^{34}$. There is a lack of awareness among public, and medical professionals have been complaining that their views have not been heard ${ }^{35}$, although NEHTA has extensively consulted with stakeholders and produced advertisements via video clips in Youtube. In the authors' discussion with potential users of individuals and healthcare providers, a few people have heard of the PCEHR system, and none can tell any of its details. In a recent Aus Health IT Poll, for the question 'Is government/NEHTA being transparent enough 
regarding the progress with the national electronic health record system?' 95\% of the participants choose 'They are excessively secretive' and the rest $5 \%$ choose 'I have no idea'.

\subsection{Opt-in Model vs Opt-out Model}

The PCEHR system adopts the opt-in model for individual's registration. The opt-in model lets an individual to make an explicit decision to participate, while the opt-out model includes an individual by default and the decision of non-participating has to be specially requested by the individual. The opt-in model places individuals at the centre of their healthcare ${ }^{24}$ since they could better control their personal information, and ensure that their health information would not be used for any purpose other than medical treatment without their permission ${ }^{36}$. However the optin model will make achieving the critical mass of adopters a really tough challenge, especially when many potential users do not understand the data that will be stored in the system and their meaningful use. It is reported that only 803 people registered in the first week, 4500 people in the first month, and as low as 6,000 in the first two months all over Australia; while the targeted user number is 500,000 within the first year of the operation of the system ${ }^{33,37,38}$. Medical professionals in Australia have voiced their concerns, and reckoned that a national EHR system should adopt the opt-out model for the targeted benefits of high quality, effective and efficient healthcare ${ }^{35,39}$.

\subsection{Privacy Concern}

Privacy concern from individuals and legal professionals is one of the top challenges to the adoption and use of the PCEHR system. It is stated by Juanita Fernando, e-health spokesperson for the Australian Privacy Foundation, that the PCEHR system would be Australia's largest and richest centralised database of private citizen information merged with Medicare and Centrelink data. Any breach of this information will affect thousands, even millions of people, in terms of their privacy and potential identity fraud $^{18}$. The safeguard of this huge volume of sensitive information will always be a very challenging task. Even though privacy risks in design and operation are identified and recommendations are provided in the Privacy Impact Assessment Report ${ }^{23}$, various stakeholders worry about the adequacy of privacy safeguards, and privacy concerns remain in public ${ }^{40}$.

The privacy concern is a main reason for many Australians not to participate in the system ${ }^{41}$. They are not sure how their sensitive medical information will be protected. According to a report on The Australian ${ }^{42}$, a recent Harris Interactive Survey confirmed this concern and found out that more than $80 \%$ of surveyed Australians had no confidence on the PCEHR system in terms of privacy and security.

It is stressed that the PCEHR system is personally controlled; however individuals cannot control their information once they withdraw from the system. According to Department of Health and Ageing ${ }^{24}$, individuals can 'remove' information, but the information will not be deleted. The information of individual withdrawers will not be deleted but deactivated, and the information can be accessed by approved purposes. Individuals do not know how the removed information may be used, and who would approve to use the deactivated information for what purposes. Moreover, organisation withdrawers are permitted to retain any information they may have previously printed or downloaded. Individuals cannot control the access to, and the PCEHR system cannot protect the printed or downloaded information.

\subsection{Effectiveness and Usability Issues}

Effectiveness and usability are the two most important characteristics for the success of any information systems. A good EHR system should be effective to achieve its objectives and must be usable (ease of use). It is reported in a survey ${ }^{43}$ of 790 staff from 65 hospitals in Australia that usability was identified as a significant factor influencing the use and frequency of use of ehealth applications. The current PCEHR system is far from mature ${ }^{27}$. The system went live in July 2012 with more than 60 high-security and critical bugs and without proper back-up and disaster recovery measures. Also it is argued that the system has not been fully tested and thus not completely functional ${ }^{33}$. The recent unstable performance of the system has caused frustration among potential users. Many people simply quit during the registration process, which is not simple and streamlined, needs to go through a few steps with different websites, and requires latest medical information of the registrant. Confronting with users' 
complaints, NEHTA indicated that PCEHR system bugs would be fixed eventually ${ }^{33}$.

Interoperability is one key issue related to the effectiveness and usability of the PCEHR system. There is a need for sharing health information among healthcare providers in order to provide the best care and clinical outcomes for healthcare receivers. The problem, however, is that many proprietary healthcare information systems store heterogeneous information in incompatible formats. These systems do not interoperate and exchange information with others in a region and/or across boundaries, and have made it difficult for national coordination ${ }^{44}$. NEHTA has put considerable efforts into addressing the interoperability issues such as service-oriented architecture (SOA) models ${ }^{45}$ for EHR framework, Health Level Seven Version 3 (HL7 v3) international standard ${ }^{46}$ for clinical document, and SNOMED CT for internal standard clinical terminology for storing and sharing health information ${ }^{24}$. Nevertheless development of a fully functional and interoperable EHR system remains a major challenge ${ }^{47}$ in terms of transferring data securely between legacy health information systems, regardless of NAHTA's attempt for a national system in the last seven years.

\section{Recommendations and Outlook}

\subsection{Value Added EHR System}

According to Department of Health and Ageing ${ }^{6}$, the PCEHR system collects clinical documents such as Shared Health Summaries, Discharge Summaries, Event Summaries, Pathology Result Reports and Specialist Letters from participating healthcare organisations, and health information entered by individuals such as overthe-counter medications. The PCEHR system indexes the clinical documents, and displays the documents or information in Index View or Consolidated View. Therefore the PCEHR system is basically a file management system.

In the authors' discussion with potential users, both medical doctors and individuals showed their concerns about such a system. These concerns include:

- It is beneficial to share some documents between doctors, but these documents may not be appropriate for patients because of their lack of medical knowledge. Patients may be worried by some medical terms.

- Clinical documents may include the information about doctors' clinical practice process. This information should not be controlled by patients. Improper use of the information may cause unpredictable consequences. Like a business process, a clinical practice process may be a doctor's intellectual property.

- Existing clinical systems work well. It is not necessary to have a new system, which costs tax payers' money, and people have to learn to use it.

- Access to information is controlled by individuals while medical organisations provide much of the information. It is very likely that the information is not allowed to be accessed at all. The organisations' effort becomes a vain attempt.

- When one piece of information is needed, the system provides a set of information. For example, a user who needs allergy details can also view medical history in the Consolidated View of the PCEHR system ${ }^{24}$. This makes it inefficient to access needed information and difficult for individuals to control the access.

- Many individuals do not understand what information is necessary for the system, and who needs which piece of information in what circumstance. They may not know what to enter into the system, and how to manage the access control.

Individuals and healthcare providers have different concerns for the PECHR system. For example, while an individual does not allow the access to certain key information because of privacy concern, doctors may worry about being responsible for medical advices provided based on the incomplete information. Also the intended purpose of efficient, safe and high quality healthcare may not be achievable as a result of the lack of required information ${ }^{15}$.

To solve these problems, the authors propose a Value Added Electronic Health Record System (VAEHRS), which is demonstrated in Figure 1. This system retains major functions of the PCEHR system: store personally identifiable (individual account) information; accept documents from existing clinical systems and allow individuals entering information; index the documents and information; display the documents in the Index View and standard summary information in Consolidated View; and other functions such as audit use of the system. However, access control is different. 


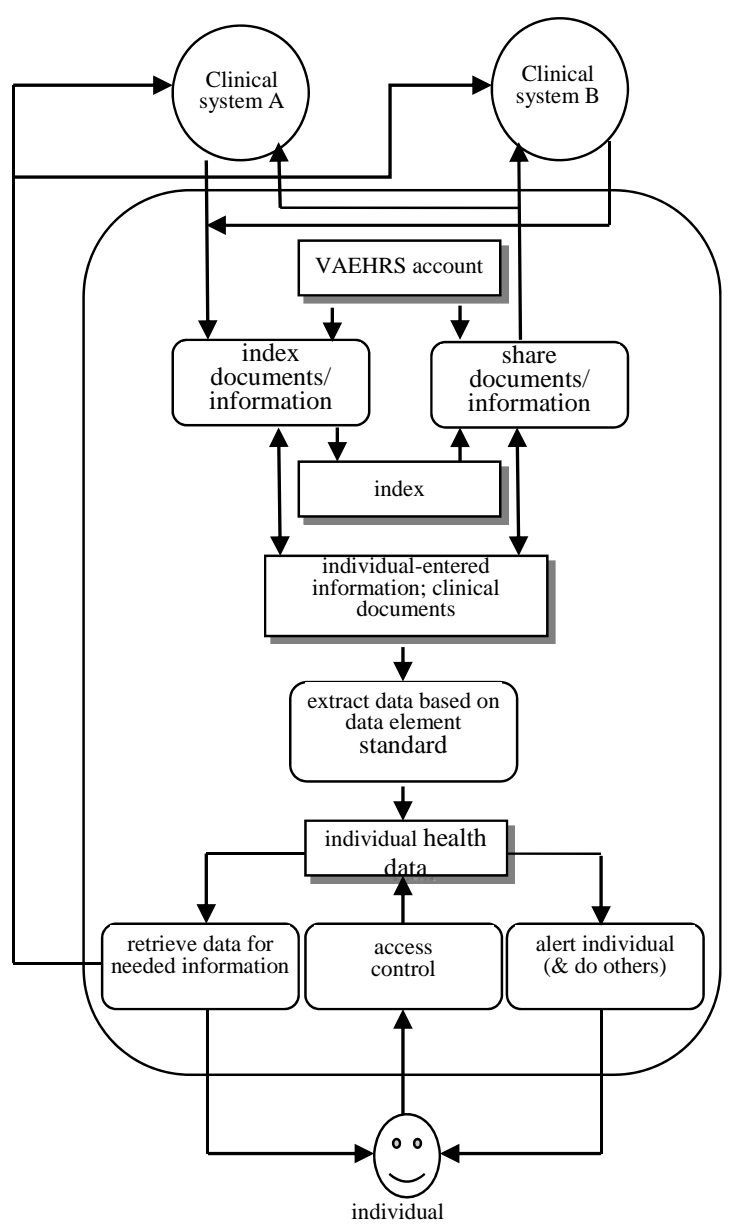

Fig 1 Value Added Electronic Health Record System

The VAEHRS adds the following functions: include a database for individual health data; extract data from the documents or information; transfer the data into the database (or update the database with the extracted data); allow both individuals and healthcare providers to control with constraints the access to the documents/information/data; allow users to retrieve data from the database to obtain needed formation; and do other activities such as alerting that amoxicillin should not be used because of the patient's allergy to penicillin.

The health record is classified into information and data according to the notion of data, information and knowledge in decision making ${ }^{48}$. The documents from clinical systems are information, from which data are extracted in accordance with a data element standard, which defines health data elements and their attributes. For example a data name can be 'allergy', and one of its attributes may be 'access_control'. The owner of the information is the information provider and the owner of the data is the individual. Contrasted with personally controlled access in the PCEHR system, access to the data/information is controlled by its owner, subject to the access attribute included in the database or index.

An essential ingredient of the VAEHRS is the data element standard, for which China's Common Data Element of Health Record ${ }^{49}$ can be referred to. The attribute values are determined based on government laws or policies, professional regulations, organisation rules, code of practice and meaningful use guideline ${ }^{50}$. The attributes can assist the individual in understanding concepts, making decisions, etc. For example, the 'access' attribute can help an individual determine access control; the 'definition' attribute provides individual-understandable definition; and 'normal_range' tells the range of normal values.

An allowed user can obtain information by retrieving only necessary data, such as 'immunisation' and 'allergy' in an emergency, without knowing other details such as medical history in Shared Health Summaries.

The VAEHRS can maintain data integrity in many cases of inconsistency or typos. For example the system can find data inconsistency of data from different sources.

\subsection{Promoting and Ensuring Wider Adoption and Continued Use}

Participation in the PCEHR system is essential for adoption and continued use of the system. The definition of the individual users affects the use of an EHR system. In the context of EHR systems, Australians, healthcare receivers, patients, individuals and consumers are used for individual users. For the PCEHR project, individual users are defined as consumers. Based on this definition, opt-in model is adopted and a consumer controls the access to his/her information regardless who is the owner of the information. Both consumers and organisations are not active in participation. The Australian government should re-define the individual users of the PCEHR system to encourage and incentivise their participation.

The PCEHR is a significant enabling component of the Government's national health reform agenda ${ }^{24}$, which targets benefits including improvement of healthcare services for Australians and reducing its 
costs. Therefore the individual users of the national EHR system should be Australian citizens instead of consumers. In the context of healthcare services, citizens assume two major roles: collective taxpayers and individual users of services ${ }^{51,52,53}$. To realise the targeted benefits, the system, which has already cost hundreds of millions of dollars of tax payers, must be used. As more than $80 \%$ of Australians strongly supported the idea of establishing an EHR system ${ }^{20}$, the national EHR system should adopt opt-out policy for the ease of inclusion in the system for majority Australian citizens.

According to Department of Health and Ageing ${ }^{24}$, individuals who decide not to have a PCEHR will not be disadvantaged in terms of their access to healthcare services. However, these individuals may consume more collective resources than those who have EHRs. For example, they may undergo the same tests with different healthcare providers. The difference in healthcare resources consumption should be considered in Medicare levy.

According to Australian and international research cited in Consumers Health Forum of Australia ${ }^{54}$, getting individuals involved in the PCEHR project from the very beginning would be helpful in winning their participation. Although NETHA has consulted with representatives of stakeholders, there is a lack of evidence of direct citizen involvement ${ }^{51}$. E-health education should be included in the national health reform agenda. The government needs to invest more resources to educate or reassure practitioners and patients about the benefits and implications of the system, and their responsibilities ${ }^{15}$. Beside newspaper discussion and online social networks, television talk/debate can be more effective for obtaining needs and concerns from stakeholders. For example, individuals may show their privacy concern; medical professionals may explain the consequence of lack of certain information; management organisations will introduce relevant laws or policies to prevent privacy violation; and system vendors will explain security techniques to protect private data.

\subsection{Keeping on Working Hard on Privacy Concerns}

The Privacy Impact Assessment Report ${ }^{23}$ identified privacy risks in terms of design and operation of the system, but may not meet the expectations of the majority of the users. For example, "for some consumers the display of their home address may [be] cause [for] concern. It should not be necessary for the PCEHR system to display this information for all consumers. We suggest that consumers have the option of leaving this field blank ...”. However, individuals may expect to know who may need it in what situation for what healthcare purposes (meaningful use and benefits); what the consequence would be if it is missing when it is needed for healthcare; what the possible misuses could be and how likely it could be misused; what the consequence would be if it is misused; what the laws or policies are to prevent it from illegal release and access; how PCEHR system protects it from unauthorised access or intruders; what the penalty/compensation is in case of illegal release, access or breach; and to which organisation the individual submits a complain. With this meta-information, an individual can balance the benefits and risks of including the information and determine the access right for it.

Adverse views on privacy have been reiterated time and time again. A lack of knowledge, mistrust, scepticism and/or caution ${ }^{51}$ may lead to the privacy concerns. It is a joint effort for risk identification and analysis by citizens, governments, medical professionals, legal professionals, information technology (IT) experts and, maybe, social psychologists to provide necessary knowledge, create individuals' trust, dispel their skepticism and relieve their caution.

Information and data in VAEHRS should be assessed, and associated risks to them in terms of privacy and security should be analysed to determine their meaningful use and appropriate access right. Individuals would be confident to participate and have guidelines to control access.

Medical professionals and legal professionals have been discussing to prevent and protect individual privacy. According to Hilvert ${ }^{38}$, the Australian Medical Association recommended that medical professionals should refuse to use a patient's EHR if that patient declines access to certain medical information associated with the record. King et al. ${ }^{36}$ pointed out that the most sensitive items of medical record have to be managed with extra caution. These items include sexually transmitted disease, abortion and infertility, family medical history, genetic disorder, mental illness, 
drug/alcohol incidents and lists of previous operations/procedures. Menachemi and Collum ${ }^{55}$ believed that although few electronic data are 100\% secure, the rigorous requirements set forth by legislation make it much more difficult for electronic data to be accessed inappropriately.

\subsection{Effective Management of Implementation}

One critical part of successful implementation of the PECHR system is effective project management. Large IT projects, including those for national EHR systems, have been infamous in expecting requirements for system capabilities, controlling the time needed to develop, test and implement as well as maintain the system, and managing project budget. According to Professor Trish Greenhalgh, University College of London $^{56}$, the failure rate of EHR projects is between $50-80 \%$, and the larger the project the more likely it fails. Scope management plays an essential role in reducing failure rate. According to their case study of successful development of EHRs in remote Australia, Cripps and Standing ${ }^{29}$ suggested that EHR projects should take a patient-centred approach and aims for a workable system rather than a perfect solution. The project for the PECHR system adopts a right approach to taking long-term view and developing the system in an evolving style.

Google Health, a personal EHR system, was recently shut down as a result of the difficulty in engaging people beyond the small group of technologically savvy patients and fitness fanatics ${ }^{12}$. Training and education for both individuals and medical professionals is necessary for the implementation of the PCEHR system. According to a Danish study on EHR implementation cited in a report by Consumers Health Forum of Australia $^{54}$, users without sufficient computing skills have difficulties in accessing needed information. Besides computing skills, individuals need to have adequate health literacy (including eHealth literacy) to effectively manage their health information. The elearning center for the PCEHR system (http://publiclearning.ehealth.gov.au), which consists of learning sites for both patients and healthcare providers, is useful for the training. Face-to-face training, especially for medical professionals and relevant staff from Medicare, Department of Health and Ageing, Department of Veteran Affairs, and other government agencies, is highly needed since those people are trusted sources of information for patients and will play important role in the adoption of the PCEHR system among health service consumers. Training and education should also be embedded in system design. Interfaces should be designed in a style that the users are familiar with (e.g. Windows interface), and help, external links and data attributes described in the VAEHRS are included as design elements. These design elements are more effective and efficient than online and face-to-face training, since instant learning is more relevant and takes limited time.

\subsection{Being Patient with the PECHR System}

According to international experiences in implementing national EHR systems, it is predicted that the uptake of the PCEHR system will be slow because of the challenges and issues identified in this paper. For example, the National Health Service in the UK has been constantly suffering from implementation problems, which lead to five years behind schedule ${ }^{57}$. The low registration rate in the last few months indicates the slow uptake.

There are 700,000 registered medical and allied professionals in Australia ${ }^{58}$. Without their participation, the PCEHR system cannot have information of high quality, and the system is only as good as an online health diaries or notebooks of individuals. From February 2013 an e-health PIP will only be available for medical practices that implement the PCEHR system ${ }^{59}$. This indicates that PCEHR will be mandatory for ehealth PIP this year. However the current immature system is not ready for use in February 2013. The Australian government is currently reviewing the suggestion by Australian Medical Association that more time for adopting the system should be given, according to a report ${ }^{15}$ on The Conversation.

The current PECHR system is additional to, but does not replace the existing clinical systems ${ }^{4,60}$. In the early years of PECHR implementation, because of the incomplete system, uncertain information quality, and learning curve, medical professionals will still go through their routine examination and do not use the PCEHR system as a solid foundation for future treatment ${ }^{18}$. As the PCEHR system obtains information from clinical systems, synchronizing the clinical systems with the PECHR system is a critical activity for doctors and patients, especially doctors, in a foreseeable future. 
Individuals who are likely to receive immediate benefit from having a PCEHR include those who have complex and chronic conditions, older Australians, Aboriginal and Torres Strait Islander peoples, mothers and their newborn children, people with mental health conditions, people with disabilities and people living in rural or remote communities ${ }^{24}$. These people may adopt PCEHR earlier than others.

\subsection{Continually Financing EHR System by Governments}

Currently, the federal government is funding general practices to develop their e-health capabilities ${ }^{25}$, and providing compensation for their efforts in filling out individuals' $\mathrm{EHR}^{61}$. This incentive measure, in addition to the mandatory use for e-health PIP, will motivate healthcare providers in using the system. After June 2014, when the funding for the period of 2012 to 2014 expires, both federal and state/territory governments should keep on taking the funding responsibility. According to Consumers Health Forum of Australia ${ }^{54}$, one recent Australian survey indicated that $88 \%$ of the participants want federal and state/territory governments to fund the PCEHR system with the federal government assuming the major funding responsibility, and $70 \%$ of them are against to the idea of contribution to the system via an annual fee. The participants of the study also pointed out the equitable access will be an issue if there is a cost for participation.

\subsection{Mobility and Social Computing Opportunities}

Accessing and managing personal health information via mobile devices should be taken into consideration. This consideration is essential for rural areas and remote communities, where physical Internet connection is not widely available, and is significant for the growing smartphone population and, more importantly, for emergent access such as that by ambulances. Currently $52 \%$ of Australians own smartphones ${ }^{62}$. Some healthcare providers have tapped into mobile health (mhealth) records, such as the reported successful case of m-health record system implemented in Kimberly, Western Australia $^{63}$. It is recommended that a portal version for mobile access to the national EHR system is developed.

Like smartphones, social network sites and online communities, such as Twitter, Linked-in, Facebook, Youtube and Wikis, have been widely used for sharing information, communication, co-creating content, cooperation and collaboration. Nowadays health social networks and online communities are mainly used for sharing ideas, discussing symptoms, and debating treatment options ${ }^{64}$. In the future, creative solutions for accessing health information via social networks and online communities should be explored for better efficiency and effectiveness of healthcare. The external links in the VAEHRS may direct users to relevant social network sites and online communities for information and knowledge. There is a need for the development of regulations on and protection measures for accessing and managing health information via mobile devices and social networks.

\subsection{Initiating Cross-Border EHR Sharing}

Cross-border EHR sharing is not in the agenda list of the implementation of the PCEHR system. International EHR sharing is very much in its infancy globally at this stage $^{65}$, but it will be embraced in the long run because the globe is becoming a village. At the moment, there exist some efforts for sharing health information electronically globally. An example is Smart Open Services for European Patients (epSOS), which is an international cross-border EHR sharing initiative and involves 23 nations. The PCEHR system should and will be adapted for cross-border EHR sharing. For this purpose, the PCEHR system should conform to international standards, such as ISO 27001 and ISO 27002 for security measures, SNOMED CT for clinical terminology, HL7 for safely exchanging medical information.

\section{Acknowledgement}

This research is supported by Australian Government under the Australia-China Science and Research Fund.

\section{References}

1. Department of Health and Ageing, The eHealth Readiness of Australia's Medical Specialists (May 2011), Online available at

http://www.health.gov.au/internet/publications/publishing. nsf/Content/CA2578620005D57ACA25790900158A0A/\$ File/Medical\%20Specialist\%20ehealth\%20readiness\%20s urvey\%20report.pdf (accessed Sep 20, 2012).

2. International Organization for Standardization (ISO), Health informatics - Electronic health record - Definition, scope, and context (2005), Online available at http://www.openehr.org/downloads/standards/iso/isotc215 
wg3 N202 ISO-TR_20514_Final_\%5B2005-0131\%5D.pdf (accessed Dec 20, 2012).

3. Australian Nursing Journal, News: National E-health rollout on. Australian Nursing Journal, 18(10) (2011) 5.

4. S. Burmester, Reviewing the Progress of eHealth in Australia, National E-Health Transition Authority (2012), Online available at http://www.nehta.gov.au/publications/whats-new (accessed Sep 12, 2012).

5. E.W. Coiera, M.R. Kidd \& M.C. Haikerwal, Editorials: A call for national e-health clinical safety governance, Medical Journal of Australia, 196(7) (2012) 430-1.

6. Department of Health and Ageing, The eHealth Readiness of Australia's Allied Health Sector (2011), Online available at

http://www.health.gov.au/internet/publications/publishing. nsf/Content/CA2578620005D57ACA2579090014230A/\$ File/Allied\%20Health\%20ehealth\%20readiness\%20survey \%20report.pdf (accessed Sep 20, 2012).

7. Internetworldstats.com, Australia: Internet Usage Stats and Telecommunications Market Report (2012), Online available at http://www.internetworldstats.com/sp/au.htm (accessed Sep 20, 2012).

8. NEHTA, Concept of Operations: Relating to the introduction of a Personally Controlled Electronic Health Record System (2011), Online available at http://www.yourhealth.gov.au/internet/yourhealth/publishi ng.nsf/Content/PCEHRS-Intro-

toc/\$File/Concept\%20of\%20Operations\%20-

\%20Final.pdf (accessed Sep 26, 2012).

9. Medicare, MediConnect (2012), Online available at http://www.medicareaustralia.gov.au/provider/patients/me diconnect.jsp (accessed Sep 27, 2012).

10. Department of Health and Ageing, HealthConnect Evaluation (2009), Online available at http://www.health.gov.au/internet/main/publishing.nsf/Co ntent/B466CED6B6B1D799CA2577F30017668A/\$File/H ealthConnect.pdf (accessed Sep 27, 2012).

11. Department of Health and Ageing, Expected Benefits of the National PCEHR System (May 2012), Online available at http://www.yourhealth.gov.au/internet/yourhealth/publishi ng.nsf/content/pcehr-benefits\#.UGARmVElp8F (accessed Sep 20, 2012).

12. D. Glance, Everything you need to know about Australia's e-health record, The Conversation, (Mar 1, 2012), Online available at http://theconversation.edu.au/everything-youneed-to-know-about-australias-e-health-records-5516 (accessed Aug 13, 2012).

13. T.J. Hannan, E-health in Australia: time to plunge into the 21st century, Medical Journal of Australia, 194(4) (2011) 211.

14. NETHA, Overview of the National eHealth Strategy and the Personally Contorlled Electronic Health Record (2012), Online available at http://www.nehta.gov.au (accessed Nov 11, 2012).
15. R. Townsend, Doctors and patients uneasy about new EHR system, The Conversation (Jul 25, 2012), Online available at http://theconversation.edu.au/doctors-andpatients-uneasy-about-new-e-health-records-system-7706 (accessed Aug 13, 2012).

16. A.K. Jha, D. Doolan, D. Grandt, T. Scott \& D.W. Bates, The use of health information technology in seven nations, International Journal of Medical Information, 77 (2008) 848-54.

17. T. Lohman, Australian e-health spending to top \$2 billion in 2010, Computerworld (Apr 15, 2010), Online available at

http://www.computerworld.com.au/article/343220/australi an_e-health_spending_top_2_billion_2010/ (accessed Sep 27, 2012).

18. K. Dearne, Sceptics warn of risks and inadequacies in shared e-health records system, The Australian (Jun 30, 2012), Online available at

http://www.theaustralian.com.au/australian-

it/government/sceptics-warn-of-risks-and-inadequacies-inshared-electronic-health-records/story-fn4htb9o1226412887806 (accessed Aug 11, 2012).

19. E. Deutsch, G. Duftschmid \& W. Dorda, Critical areas of national electronic health record programs: Is our focus correct, International Journal of Medical Informatics, 79 (2010) 211-22.

20. NEHTA, Report for Quantitative Survey in July 2008, (2008), Online available at http://www.nehta.gov.au/index.php?option=com_docman \&task=doc_details\&gid=585\&Itemid=139\&catid $=130$ (accessed Aug 16, 2012).

21. Deloitte, National E-Health Strategy (2008), Online available at

http://www.health.gov.au/internet/main/publishing.nsf/Co ntent/National+Ehealth+Strategy (accessed Jan 18, 2013).

22. Attorney-General's Department, Healthcare Identifiers Act 2010 (2010), Online available at http://www.comlaw.gov.au/Details/C2012C00590 (accessed Sep 26, 2012).

23. Department of Health and Ageing, Privacy Impact Assessment Report (2011), Online available at http://www.yourhealth.gov.au/internet/yourhealth/publishi ng.nsf/Content/pcehr-legals-pia/\$File/PCEHR-PrivacyImpact-Assessment-Report.pdf (accessed Aug 17, 2012).

24. Department of Health and Ageing, Concept of Operations: Relating to the introduction of a Personally Controlled Electronic Health Record System (2011), Online available at http://www.yourhealth.gov.au/internet/yourhealth/publishi ng.nsf/Content/CA2578620005CE1DCA2578F800194110 /\$File/PCEHR-Concept-of-Operations-1-0-5.pdf (accessed Sep 30, 2012).

25. K. McDonald, Use it or lose it - PCEHR for PIP, Pulse+IT (May 9, 2012), Online available at http://www.pulseitmagazine.com.au/index.php?option=co m_content\&view=article\&id=983:use-it-or-lose-it-pcehrfor-pip\&catid=16:australian-ehealth\&Itemid $=328$ (accessed Sep 25, 2012). 
26. G. Bloom, The National Systems of Personally Controlled Electronic Health Records, HWL Ebsworth (Oct 17, 2012), Online available at http://www.hwlebsworth.com.au/latest-news-apublications/publications/health/item/756-the-nationalsystem-of-personally-controlled-electronic-healthrecords.html (accessed Nov 30, 2012).

27. J. Gliddon, Opposition votes for ehealth, slams PCEHR, eHealthSpace (Feb 5, 2012), Online available at http://ehealthspace.org/news/opposition-votes-ehealthslams-pcehr (accessed Sep 25, 2012).

28. NEHTA, About the PCEHR system (2012) Online available at http://www.ehealthinfo.gov.au/personallycontrolled-electronic-health-records/about-the-pcehrsystem (accessed Sep 25, 2012).

29. H. Cripps \& C. Standing, The implementation of electronic health records: A case study of bush computing the Ngaanyatjarra Lands, International Journal of Medical Informatics, 80 (2011) 841-8.

30. K. Dearne, Personally controlled electronic health record system coming, The Australian; (Nov 23, 2011), Online available at http://www.theaustralian.com.au/australianit/government/personally-controlled-electronic-healthrecord-system-coming/story-fn4htb9o-1226203867730 (accessed Aug 14, 2012).

31. B. Winterford, Report urges electronic health records by 2012, iTnews (Jul 7, 2009), Online available at http://www.itnews.com.au/News/151290,report-urgeselectronic-health-records-by-2012.aspx (accessed Mar 2, 2012).

32. A. Sheikh, T. Cornford, N. Barber, A. Avery, A. Takian, V. Lichtner, et al. Implementation and adoption of nationwide electronic health records in secondary care in England: Final qualitative results from perspective national evaluation in early adopter hospitals, BMJ Group (Oct 17, 2011), Online available at http://www.bmj.com/content/341/bmj.c4564 (accessed Aug 16, 2012).

33. F. Foo, Some PCEHR bugs will be fixed after go-live, says NEHTA, The Australian (Aug 1, 2012), Online available at http://www.theaustralian.com.au/australianit/government/some-pcehr-bugs-will-be-fixed-after-golive-says-nehta/story-fn4htb9o-1226440424847 (accessed Sep 26, 2012).

34. F. Foo, Department keep details secret, The Australian (Nov 27, 2012), Online available at http://www.theaustralian.com.au/australianit/government/department-keeps-details-secret/storyfn4htb9o-1226524460937 (accessed Nov 30, 2012).

35. J. Taylor, Slow uptake better for e-health: Roxon, ZDNet (Sep 13, 2011), Online available at http://www.zdnet.com/slow-uptake-better-for-e-healthroxon-1339322154/ (accessed Mar 2, 2012).

36. T. King, L. Brankovic \& P. Gillard, Perspectives of Australian adults about protecting the privacy of their health information in statistical database, International Journal of Medical Information, 81 (2012) 279-89.
37. K. McDonald, 803 Sign up in PCEHR's first week, Pulse+IT (Jul 9, 2012), Online available at http://www.pulseitmagazine.com.au/index.php?option=co m_content\&view=article\&id=1068:803-sign-up-inpcehrs-first-week\&catid=16:australianehealth\&Itemid=328 (accessed Sep 27, 2012).

38. J. Hilvert, Doctors could reject e-health records, ITNews (Sep 20, 2012), Online available at http://www.itnews.com.au/News/316321, doctors-couldreject-e-health-records.aspx (accessed Nov 30, 2012).

39. AMA, Draft Guide to Using the PCEHR (2012), Online available at http://ama.com.au/media/draft-guide-usingpcehr (accessed Sep 26, 2012).

40. K. Dearne, Concerns raised over e-health plan, Australian IT (Mar 20, 2012), Online available at http://www.theaustralian.com.au/australianit/government/concerns-raised-over-e-health-plan/storyfn4htb9o-1226304939750 (accessed Aug 11, 2012).

41. eHealth Division, Draft Concept of Operations: Relating to the Introduction of a PCEHR System (2011), Online available at

http://www.yourhealth.gov.au/internet/yourhealth/publishi ng.nsf/Content/CA2578620005CE1DCA2579040005A91 C/\$File/Draft\%20Concept\%20of\%20Operations\%20Feed back\%20Report.pdf (accessed Sep 26, 2012).

42. K. Dearne, Shift to medical e-records worries majority of Australians with sensitive medical information, The Australian (Sep 20, 2011), Online available at http://www.theaustralian.com.au/australian-it/shift-tomedical-e-records-worries-majority-of-australians-withsensitive-medical-information/story-e6frgakx1226141212027 (accessed Mar 2, 2012).

43. A.S. Gosling \& J.I. Westbrook, Allied health professionals' use of online evidence: a survey of 790 staff working in the Australian public hospital system, International Journal of Medical Informatics, 73 (2004) 391-401.

44. C. Pearce \& M.C. Haikerwal, E-health in Australia: time to plunge into the 21st century, Medical Journal of Australia, 193(7) (2010) 397-8.

45. M.N. Huhns \& M.P. Singh, Service-oriented computing: Key concepts and principles, IEEE Internet Computing, 9(1) (2005) 75-81.

46. HL7, Health Level 7 (HL7) (2007), Online available at http://www.hl7.org (accessed Sep 30, 2012).

47. B.L. Srur \& S. Drew, Challenges in designing a successful e-health system for Australia, International Symposium on Information Technology in Medicine and Education (ITME) (Gold Coast, Australia, 2012) 480-484.

48. H. Du, Data Mining Techniques and Applications: An Introduction, Cengage Learning (Hampshire U.K., 2010).

49. Ministry of Health, Common Data Element of Health Record (2009), Online available at http://www.chima.org.cn/pe/Article/ShowArticle.asp?Arti cleID=761 (accessed Aug 8, 2012). 
50. D. Blumenthal \& M. Tavenner, The "Meaningful Use" Regulation for Electronic Health Records, The New England Journal of Medicine, 363(6) (2010) 501-4.

51. C.M. Showell, Citizens, patients and policy: a challenge for Australia's national electronic health record, Health Information Management Journal, 40(2) (2011) 29-43.

52. J. Church, D. Saunders, M. Wanke, R. Pong, C. Spooner \& M. Dorgan, Citizen participation in health decisionmaking: past experience and future prospects, Journal of Public Health Policy, 23(1) (2002) 12-32.

53. C. Tuohy \& R. Evans, Pushing on a string: the decentralization of health planning in Ontario, In R. Gotembiewski \& A. Wildavsky eds. The Costs of Federalism, Transaction Books (New Brunswick NJ, 1986).

54. Consumers Health Forum of Australia, e-Health and Electronic Health Records: Current Consumer Research (2011), Online available at https://www.chf.org.au/pdfs/rep/rep-691-eHealthresearchfeb11.pdf (accessed Aug 14, 2012).

55. N. Menachemi \& T.H. Collum, Benefits and drawbacks of electronic health record systems, Risk Management and Healthcare Policy, 4 (2011) 47-55.

56. D. Manos, Electronic health records not a panacea, researchers say, Healthcare IT News (Dec 14, 2009), Online available at

http://www.healthcareitnews.com/print/11468 (accessed Feb 21, 2012).

57. N. Bourlioufas, E-health System May Be Doomed, Australian Doctors' Fund Blog, (Feb 22, 2010), Online available at www.adf.com.au/wordpress/?p=262 (accessed Feb 28, 2012).

58. K. Hagan, Electronic health record planned, The Age (Mar 30, 2011), Online available at http://www.theage.com.au/action/printArticle?id=2258839 (accessed Aug 14, 2012).

59. C. Jackson, The personally controlled electronic health record (PCEHR) - decision time approaching for general practitioners and practices (The Royal Australian College of General Practitioners, May 22, 2012), Online available at http://www.racgp.org.au/news/46973 (accessed Sep 26, 2012).

60. The Royal Australian College of General Practitioners, Personally controlled electronic health record: Putting the PCEHR into practice (May 22, 2012), Online available at http://www.racgp.org.au/your-practice/e-

health/ehealthrecords/pcehr/intopractice/ (accessed Nov 30, 2012).

61. S. Tindal, GPs win e-health concessions, ZDNet, (Aug 22, 2012), Online available at http://www.zdnet.com/au/gpswin-e-health-concession-7000003026/ (accessed Dec 2, 2012).

62. M. Ross, Smartphone penetration booms down under, $B \& T$, (May 16, 2012), Online available at http://www.bandt.com.au/news/digital/smartphonepenetration-booms-down-under (accessed Sep 26, 2012).
63. J. Gliddon, Mobile health records connect outback communities, eHealthSpace (Feb 24, 2012), Online available at http://ehealthspace.org/casestudy/mobilehealth-records-connect-outback-communities (accessed Aug 13, 2012).

64. R. Gaganayake, R. Iannella \& T. Sahama, Sharing with care: An information accountability perspective, IEEE Internet Computing (Jul/Aug, 2011) 31-38.

65. V.J. Vest, Health Information Exchange: National and International Approaches, Adv Health Care Manag, 12 (2012) 3-24. 